\title{
Optimizing a Novel Method for Synthesizing Gold Nanoparticles: Biophysical Studies
}

\author{
Mohamed Anwar K. Abdelhalim*
}

Department of Physics and Astronomy, College of Science, King Saud University, Saudi Arabia

\begin{abstract}
Background: The properties of Gold Nanoparticles (GNPs) make them useful for cancer therapy, diagnostics and imaging. For the application of GNPs in therapy and drug delivery there is a great necessity to synthesize known particle size of GNPs with simple methods. This study aimed to optimize a novel simple method for synthesizing GNPs.
\end{abstract}

Methods: GNPs were synthesized by using different citrate concentrations (40, 100 and $150 \mathrm{mM})$ through reduction of hydrogen tetrachloroaurate $\left(\mathrm{HAuCl}_{4}\right)$ of varying concentrations. The synthesized GNPs were characterized with transmission electron microscope, UV-Vis spectrophotometer, and size distributions with dynamic light scattering.

Results: At $40 \mathrm{mM}$ citrate concentration, different particle sizes $(18-28 \mathrm{~nm})$, non-round and not homogenous GNPs were formed; at $100 \mathrm{mM}$ citrate concentration, more round GNPs were formed and the particle size reduced to nearly $12 \mathrm{~nm}$ with very narrow particle size distribution; at $150 \mathrm{mM}$ citrate concentration, the GNPs size increased up to $18 \mathrm{~nm}$ and the homogeneity of the particle size distribution reduced as indicted from both Transmission Electron Microscopy (TEM) image and distribution profile. When $\mathrm{HAuCl}_{4}$ concentration increased from 1 to $4 \mathrm{mM}$, the particle size of GNPs increased from $12 \mathrm{~nm}$ to nearly $20 \mathrm{~nm}$, respectively.

Conclusions: At $40 \mathrm{mM}$ citrate concentration, the coverage of citrate is incomplete and the aggregation process leads to the formation of inhomogenous GNPs; at $100 \mathrm{mM}$ citrate concentrations, the citrate behaves as a pH mediator explains the reduction of the particle size. The increase of $\mathrm{HAuCl}_{4}$ concentration causes retardation of the nucleation step forming lower number of nuclei in the solution and thus increases the final particle size and polydispersity.

Keywords: Gold nanoparticles; Colloids; Hydrogen tetrachloroaurate; Synthesis mechanism; Sodium hydroxide

\section{Introduction}

Gold in its bulk form has been considered an inert, noble metal with some therapeutic and medicinal value. The GNPs have found widespread applications in life sciences and attracted significant research interest. The GNPs have been widely exploited for use in Surface Enhanced Raman Scattering (SERS) [1], imaging [2], biological applications [3] and photothermal effects [4].

There are many physical and chemical processes for synthetizing GNPs. The extensively used procedures to synthesize GNPs in aqueous solutions are the reduction of ionic gold by adding the sodium citrate, sodium borohydride, ascorbic acid and tannic acid [5].

The synthesis of GNPs without reducing agents or templates has induced exciting interest for material and chemical researchers. The synthesis of extremely stable size-controlled GNPs without the use of any reducing agents in the presence of Polyvinylpyrrolidone (PVP) has been reported [6].

Polymers and/or ionic surfactants are used as capping agents in aqueous-solution systems to prepare the nanomaterials. Cationic surfactants such as Hexadecyl trimethyl ammonium bromide (CTAB) are usually used in aqueous solution to synthesize anisotropic GNPs $[7,8]$.

Abdelhalim, 2011 and 2012 [9-11], Abdelhalim and Jarrar, 2011 and 2012 [12-16] have reported the side effects, bioaccumulation and toxicity induced by intraperitoneal administration of GNPs in several rat tissues in vivo.
In order to understand and categorize the mechanisms of NPs toxicity, information is needed on the response of living systems to the presence of NPs of varying size, shape, surface and bulk chemical composition. Very little information on these aspects is presently available and this implies an urgent need to find novel simple methods for synthesizing GNPs.

It is important to synthesize and optimize novel and simple high quality GNPs. In certain applications, it is also important to prepare GNPs of high concentrations. Therefore, the goal of this work is to develop a new approach to synthesize GNPs of high quality and high concentration that are appropriate for preparation of GNPs conjugates [17].

In this study, the GNPs will be synthesized and optimized by adding different citrate concentrations to hydrogen tetrachloroaurate $\left(\mathrm{HAuCl}_{4}\right)$ of varying concentrations. The synthesized GNPs will be characterized with TEM and UV-Vis spectrophotometer while the

*Corresponding author: Dr. Mohamed Anwar K. Abdelhalim, Department of Physics and Astronomy, College of Science, King Saud University, P.O 2455, Riyadh 11451, Saudi Arabia, E-mail: abdelhalimmak@yahoo.com, mabdulhleem@ksu.edu.sa

Received March 30, 2012; Accepted May 02, 2012; Published May 04, 2012

Citation: Abdelhalim MAK (2012) Optimizing a Novel Method for Synthesizing Gold Nanoparticles: Biophysical Studies. J Cancer Sci Ther 4: 140-143. doi:10.4172/1948-5956.1000128

Copyright: (C) 2012 Abdelhalim MAK. This is an open-access article distributed under the terms of the Creative Commons Attribution License, which permits unrestricted use, distribution, and reproduction in any medium, provided the original author and source are credited. 
GNPs particle size distributions will be characterized by the dynamic light scattering.

\section{Synthesizing Gold Nanoparticles (GNPs)}

The GNPs were prepared by citrate reduction of $\mathrm{HAuCl}_{4}[18]$. An aqueous solution of $\mathrm{HAuCl}_{4}(100 \mathrm{~mL}: 1$ and $4 \mathrm{mM})$ was refluxed for 5-10 min and warmed at $\left(50-60^{\circ} \mathrm{C}\right)$ aqueous solution of sodium citrate (10 mL: 40,100 and $150 \mathrm{mM}$ ) was added quickly. Reflux was continued for another $30 \mathrm{~min}$ until a deep red solution was observed. The solution was filtered through $0.45 \mu \mathrm{m}$ Millipore syringe filters to remove any precipitates. The $\mathrm{pH}$ was adjusted to 7 using dilute $\mathrm{NaOH}$ solution, and the filtrate was stored at room temperature [19]. The solutions were induced dark red color with a maximum of absorbance centered at 520 $\mathrm{nm}$.

\section{Characterization of Gold Nanoparticles (GNPs)}

The synthesized GNPs were characterized with transmission electron microscopy (TEM: JEOL JSM-2100F electron microscope operated at $200 \mathrm{kV}$ ) and UV-Vis spectrophotometer (Spectro UVD3500: SPECTRO UV-VIS DOUBLE BEAM RESEARCH SPECTROPHOTOMETER VARIABLE BANDWIDTH; LABOMED, INC. USA). GNPs size distributions were measured by dynamic light scattering (Malvern Nanosizer ZS instrument).

\section{Results and Discussions}

\section{Effect of sodium citrate concentration}

TEM images in Figure 1 show the formation of GNPs at different sodium citrate concentrations. It is clear in this study that at low citrate concentration $(40 \mathrm{mM})$, different particles size and non-round GNPs were formed. The particle size was ranged from 18-28 nm and not homogenous as shown in the particle size distribution (Figure 1a). Addition of $100 \mathrm{mM}$ citrate solution resulted in gold formation of more round GNPs. The particle size was reduced to be around $12 \mathrm{~nm}$ with very narrow particle size distribution (Figure 1b). Further increase of citrate solution to $150 \mathrm{mM}$ caused the GNPs to increase in size up to $18 \mathrm{~nm}$. However, the homogeneity of the particle size distribution was reduced as indicted from both TEM image (Figure 1c) and distribution profile (inset).

In the preparation of GNPs by citrate reduction, citrate acts as both reducing and stabilizing agent. The adsorption of citrate on the particles as a stabilizer significantly affects the particle size band. The role of citrate increases the complexity of the particle preparation process. At lower citrate concentration $(40 \mathrm{mM})$, the coverage of citrate is incomplete and the aggregation process leads to form inhomogenous GNPs. On the other hand, at high citrate concentrations (100 and 150 $\mathrm{mM}$ ), the behavior of citrate as a $\mathrm{pH}$ mediator explains the tendency of stabile particle size.

Citrate is known as a weak base which can change the solution $\mathrm{pH}$ to a certain extent with its concentration. The $\mathrm{pH}$ of the solution increases as the citrate concentration increases. Subsequently, the less reactive complexes $\left[\mathrm{AuCl}_{2}(\mathrm{OH})_{2}\right]^{-}$and $\left[\mathrm{AuCl}(\mathrm{OH})_{3}\right]^{-}$are formed by the hydrolysis of $\mathrm{AuCl}_{4}^{-}$, consequently, the nucleation rate becomes slower and the amount of Au precursor remaining in the solution becomes larger. The final particle size is determined by the diffusional growth of $\mathrm{Au}$ precursor on the surface of Au nuclei. It has been reported that using an excessive amount of citrate, the final particle size increases a little [20].

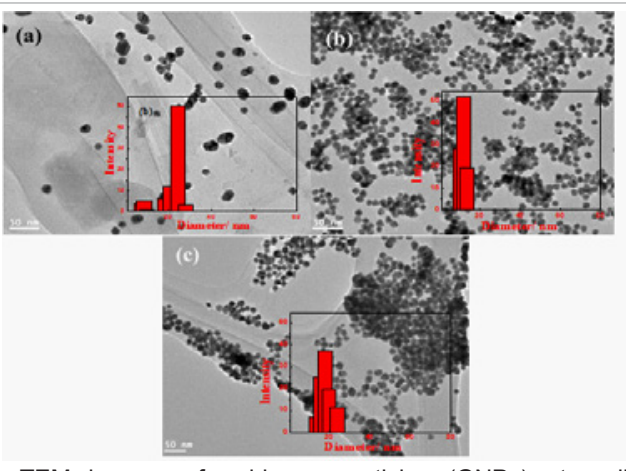

Figure 1: TEM images of gold nanoparticles (GNPs) at sodium citrate concentrations of (a) 40, (b) 100 , and (c) $150 \mathrm{mM}$ and $1 \mathrm{mM} \mathrm{HAuCl}_{4}$, (inset) their corresponding particle size distribution.

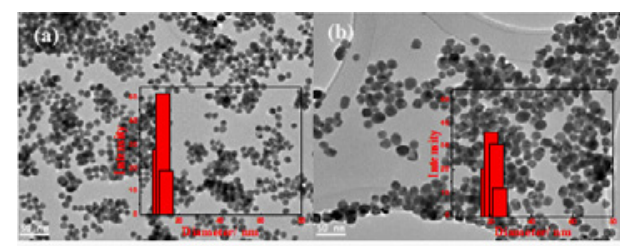

Figure 2: TEM images of gold nanoparticles (GNPs) at $\mathrm{HAuCl}_{4}$ of (a) 1 and (b) $4 \mathrm{mM}$ and $100 \mathrm{mM}$ sodium citrate, (inset) their corresponding particle size distribution.

\section{Effect of $\mathrm{HAuCl}_{4}$ concentration}

Variation of $\mathrm{HAuCl}_{4}$ concentration was also significant in tuning the particle size and polydispersity of GNPs. The increase of $\mathrm{HAuCl}_{4}$ from 1 to $4 \mathrm{mM}$ (Figure 2: $2 \mathrm{a}$ and 2b, respectively), caused growth of particle size of GNPs from $12 \mathrm{~nm}$ to nearly about $20 \mathrm{~nm}$, respectively. On other hand, the particle size distribution tended to become broader with increasing $\mathrm{HAuCl}_{4}$ concentration which means more polydisperse particles are formed.

The increase of $\mathrm{HAuCl}_{4}$ concentration means decrease in the corresponding amount of citrate (reducing agent) which in turn might cause the retardation of the nucleation step and the reduction in the number of nuclei in the solution resulting in an increase in the final particle size and the polydispersity [21].

The synthesized GNPs are further characterized by UV-Vis spectrophotometer at the room temperature. Table 1 shows UV-VIS spectrum for different $\mathrm{Au}(1$ and $4 \mathrm{mM})$ and citrate (40, 100 and 150 $\mathrm{mM}$ ) concentrations. Table 1 indicates that when Au increases from 1 $\mathrm{mM}$ (at citrate concentration: 40,100 and $150 \mathrm{mM}$ )) to $4 \mathrm{mM}$ (at citrate concentration $100 \mathrm{mM}$ )), the peak shifted from 527, 523 and 523 to $530 \mathrm{~nm}$, respectively. Table 1 also shows a typical surface absorption band $\left(\lambda_{\max }\right)$ at about 523, 527 and $530 \mathrm{~nm}$ for GNPs dependent on Au and citrate concentrations. Because of the special shape and structure of GNPs, it often exhibited distinctive SPR peaks in the UV-Visible region, which was coincident with the plasmon band of the spherical GNPs [22,23] (Figure 3 and 4).

Indeed, it is well established that at $100 \mathrm{mM}$ citrate concentration and with increasing Au from 1 to $4 \mathrm{mM}$ concentration, the band width increased from 110 to 190 accompanied with a decrease in the absorbance from 0.60 to 0.28 and an increase in particle size of GNPs from 12 to $18 \mathrm{~nm}$. Table 1 also indicates that at $100 \mathrm{mM}$ citrate concentration and $4 \mathrm{mM}$ Au concentration, 256, 530, 772 peaks were 
Citation: Abdelhalim MAK (2012) Optimizing a Novel Method for Synthesizing Gold Nanoparticles: Biophysical Studies. J Cancer Sci Ther 4: 140-143. doi:10.4172/1948-5956.1000128

observed with $0.43,0.28$ and 0.29 absorbances and 50, 65 and 190 bandwidths, respectively.

The bandwidth is inversely proportional to the particle size smaller than about $20 \mathrm{~nm}$ and the plasmon absorption maximum is red-shifts with increasing particle size [22,23].

This study suggests that additional synthesizing methods of GNPs are needed without using reducing agents; such as the addition of different sodium hydroxide $(\mathrm{NaOH})$ concentrations to $\mathrm{HAuCl}_{4}$ and Hexadecyl trimethyl ammonium bromide (CTAB). In addition to the comparison that must be done between both of the 2 methods. Moreover, additional experiments are now performed taken in

\begin{tabular}{|l|l|l|l|}
\hline Concentration & Peak $(\mathrm{nm})$ & Absorbance & Band width $(\mathrm{nm})$ \\
\hline 1mM Au \& 40 mM citrate & 527 & 0.51 & 140 \\
\hline 1mM Au \& $100 \mathrm{mM}$ citrate & 523 & 0.6 & 110 \\
\hline 1mM Au \& $150 \mathrm{mM}$ citrate & 523 & 0.27 & 100 \\
\hline 4mM Au \& 100 mM citrate & $256,530,772$ & $0.43,0.28,0.29$ & $50,65,190$ \\
\hline
\end{tabular}

Table 1: UV-VIS spectrum for different Au and citrate concentrations.

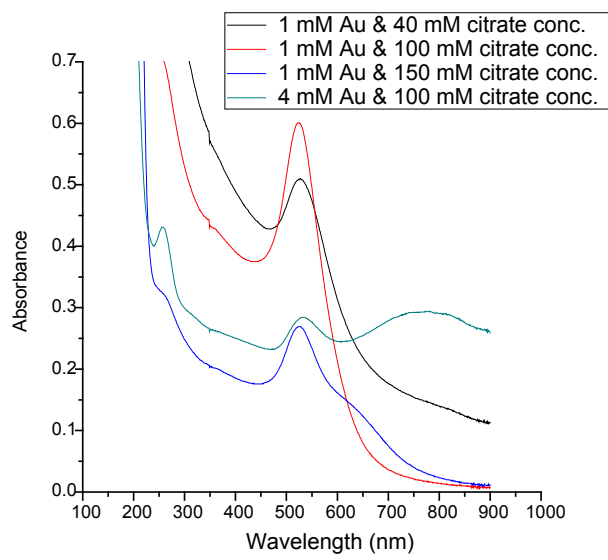

Figure 3: The absorbance of synthesized gold nanoparticles at different citrate and gold concentrations against the wavelength $(\mathrm{nm})$.

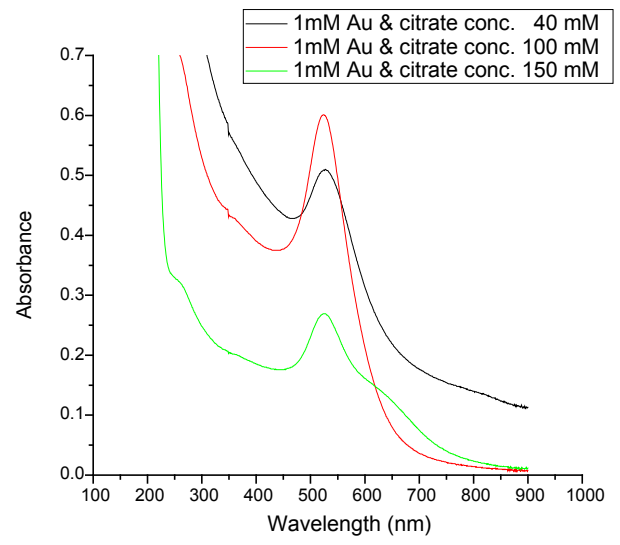

Figure 4: The absorbance of synthesized gold nanoparticles at different citrate and gold concentrations against the wavelength $(\mathrm{nm})$. consideration the use of GNPs as diagnostic and therapeutic tool for treatment of the cancer disease.

\section{Conclusions}

This study aimed to optimize a novel simple method for synthesizing GNPs in an attempt to cover and understand the potential role of GNPs as a therapeutic and diagnostic tool.

The GNPs were synthesized and optimized by using different citrate and $\mathrm{HAuCl}_{4}$ concentrations. At $40 \mathrm{mM}$ citrate concentration, different particle sizes $(18-28 \mathrm{~nm})$, non-round and not homogenous GNPs were formed due to the incomplete citrate and the aggregation process leads to the formation of inhomogenous GNPs; at $100 \mathrm{mM}$ citrate concentration, more round GNPs were formed and the particle size reduced to nearly $12 \mathrm{~nm}$ with very narrow particle size distribution whereas the citrate behaves as a $\mathrm{pH}$ mediator explaining the reduction of the particle size; at $150 \mathrm{mM}$ citrate concentration, the GNPs size increased up to $18 \mathrm{~nm}$ and the homogeneity of the GNPs size distribution was reduced as indicted from both TEM image and distribution profile.

$\mathrm{HAuCl}_{4}$ concentration was also significant in tuning the particle size and polydispersity of GNPs. When $\mathrm{HAuCl}_{4}$ concentration increased from 1 to $4 \mathrm{mM}$, the particle size of GNPs increased from 12 $\mathrm{nm}$ to nearly $20 \mathrm{~nm}$, respectively.

This study suggests the formation of less reactive complexes by hydrolysis of $\mathrm{AuCl}_{4}^{-}$, consequently, the nucleation rate becomes slower and the amount of Au precursor remaining in the solution becomes larger. Because of using an excessive amount of citrate, the final particle size increases a little. The increase of $\mathrm{HAuCl}_{4}$ concentration means decrease in the corresponding amount of citrate (reducing agent), resulting in an increase in the final GNPs size and the polydispersity.

\section{Competing Interests}

Author declares that he has no competing interests.

\section{Author's Contributions}

Mohamed Anwar K. Abdelhalim has analyzed data, interpreted and written the final draft of this manuscript. The animal model used in this study was obtained from the Laboratory Animal Center (College of Pharmacy, King Saud University, Saudi Arabia). Abdelhalim MAK has conceived the study and its design and obtained research grants for this study. The authors have read and approved the final manuscript.

\section{Acknowledgements}

The author is very grateful to the National Plan of Science and Technology (NPST). This research was financially supported by the National Science and Technology Innovation Plan (NSTIP), Research No. 08-ADV206-02 and Research No. 09-NAN670-02, College of Science, King Saud University, Saudi Arabia.

\section{References}

1. Zhang DF, Zhang Q, Niu LY, Jiang L, Yin PG, et al. (2011) Self-assembly of gold nanoparticles into chain-like structures and their optical properties. $J$ Nanopart Res 13: 3923-3928.

2. Mani V, Chikkaveeraiah BV, Patel V, Gutkind JS, Rusling JF (2009) Ultrasensitive immunosensor for cancer biomarker proteins using gold nanoparticle film electrodes and multienzyme-particle amplification. ACS Nano 3: 585-594.

3. Park SJ, Taton TA, Mirkin CA (2002) Array-based electrical detection of DNA with nanoparticle probes. Science 295: 1503-1506.

4. Llorca J, Casanovas A, Dominguez M, Casanova I, Angurell I, et al. (2008) Plasma-activated core-shell gold nanoparticle films with enhanced catalytic properties. J Nanopart Res 10: 537-542. 
Citation: Abdelhalim MAK (2012) Optimizing a Novel Method for Synthesizing Gold Nanoparticles: Biophysical Studies. J Cancer Sci Ther 4: 140-143. doi:10.4172/1948-5956.1000128

5. Daniel MC, Astruc D (2004) Gold nanoparticles: assembly, supramolecular chemistry, quantum-size-related properties, and applications toward biology, catalysis, and nanotechnology. Chem Rev 104: 293-346.

6. Zhou M, Wang B, Rozynek Z, Xie Z, Fossum JO, et al. (2009) Minute synthesis of extremely stable gold nanoparticles. Nanotechnology 20: 505606

7. Ming Chen H, Liu RS, Tsai DP (2009) A Versatile Route to the Controlled Synthesis of Gold Nanostructures. Cryst Growth Des 9: 2079-2087.

8. Sau TK, Murphy CJ (2004) Seeded high yield synthesis of short Au nanorods in aqueous solution. Langmuir 20: 6414-6420.

9. Abdelhalim MA (2011) Exposure to gold nanoparticles produces cardiac tissue damage that depends on the size and duration of exposure. Lipids Health Dis 10: 205 .

10. Abdelhalim MA (2011) Gold nanoparticles administration induces disarray of heart muscle, hemorrhagic, chronic inflammatory cells infiltrated by small lymphocytes, cytoplasmic vacuolization and congested and dilated blood vessels. Lipids Health Dis 10: 233.

11. Abdelhalim MA (2012) Exposure to gold nanoparticles produces pneumonia fibrosis, chronic inflammatory cell infiltrates, congested and dilated blood vessels, and hemosiderin granule and emphysema foci. J Cancer Sci Ther 4 : 046-050.

12. Abdelhalim MA, Jarrar BM (2011) Gold nanoparticles administration induced prominent inflammatory, central vein intima disruption, fatty change and Kupffer cells hyperplasia. Lipids Health Dis 10:133.

13. Abdelhalim MA, Jarrar BM (2011) The appearance of renal cells cytoplasmic degeneration and nuclear destruction might be an indication of GNPs toxicity. Lipids Health Dis 10:147.

14. Abdelhalim MA, Jarrar BM (2011) Renal tissue alterations were size-dependent with smaller ones induced more effects and related with time exposure of gold nanoparticles. Lipids Health Dis 10: 163.
15. Abdelhalim MA, Jarrar BM (2011) Gold nanoparticles induced cloudy swelling to hydropic degeneration, cytoplasmic hyaline vacuolation, polymorphism, binucleation, karyopyknosis, karyolysis, karyorrhexis and necrosis in the liver. Lipids Health Dis 10: 166.

16. Abdelhalim MA, Jarrar BM (2012) Histological alterations in the liver of rats induced by different gold nanoparticle sizes, doses and exposure duration. $J$ Nanobiotechnology 10: 5 .

17. Liang Z, Zhang J, Wang L, Song S, Fan C, et al. (2007) A centrifugation-based method for preparation of gold nanoparticles and its application in biodetection. Int J Mol Sci 8: 526-532.

18. Lévy R, Thanh NT, Doty RC, Hussain I, Nichols RJ, et al. (2004) Rational and combinatorial design of peptide capping ligands for gold nanoparticles. J Am Chem Soc 126:10076-10084.

19. Kogan MJ, Bastus NG, Amigo R, Grillo-Bosch D, Araya E, et al. (2006) Nanoparticle-mediated local and remote manipulation of protein aggregation Nano Lett 6: 110-115.

20. Ji X, Song X, Li J, Bai Y, Yang W, et al. (2007) Size control of gold nanocrystals in citrate reduction: the third role of citrate. J Am Chem Soc 129: 13939-13948.

21. Kimling J, Maier M, Okenve B, Kotaidis V, Ballot H, et al. (2006) Turkevich method for gold nanoparticle synthesis revisited. J Phys Chem B 110: 1570015707.

22. Link S, El-Sayed MA (1999) Size and temperature dependence of the plasmon absorption of colloidal gold nanoparticles. J Phys Chem B 103: 4212-4217.

23. Link S, El-Sayed MA (1999) Spectral properties and relaxation dynamics of surface plasmon electronic oscillations in gold and silver nanodots and nanorods. J Phys Chem B 103: 8410-8426. 